\title{
A prática dos tutores em um programa de formação pedagógica a distância: avanços e desafios
}

\author{
Maria de Fátima S. O. Barbosa ${ }^{1}$
}

Flavia Rezende 2

BARBOSA, M. F. S. O.; REZENDE, F. Tutors' experience in a distance educational program: progress and challenges. Interface - Comunic., Saúde, Educ., v.10, n.20, p.473-86, jul/dez 2006.

This study was carried out among nursing professionals engaged in distance educational program, and it sought identify the tutor's experience, the obstacles and challenges they dealt with the distance program. The main obstacles mentioned by tutors included: difficulty to assimilate the constructivist pedagogical concepts in their activities (translate the course lessons to practice); difficulty in assimilating new technologies; lack of adequate telecommunications infrastructure in many towns; lack of time to develop course activities. Tutors believe that it was a challenging experience, since there was no model to follow. These results indicate that tutors haven't culturally assimilated distance education and overcoming the distance can be even more difficult for nursing professionals given that in many cases they have double shifts.

KEY WORDS: distance education. professional education. nursing. preceptorship.

Este trabalho foi realizado no âmbito de um programa de formação pedagógica a distância de trabalhadores da área de enfermagem, buscando conhecer a prática dos tutores e os obstáculos e desafios enfrentados por eles na ação educativa a distância. Os obstáculos apontados pelos tutores foram: dificuldade em assimilar a concepção pedagógica construtivista nas atividades de tutoria (transpor a proposta pedagógica para a prática); dificuldade no uso das tecnologias; falta de infra-estrutura de telecomunicações de alguns municípios; dificuldade em realizar atividades necessárias ao desenvolvimento do curso em função da falta de tempo. Os tutores consideraram um desafio desempenhar a tutoria, por ser uma experiência nova para a qual não há modelo predefinido a seguir. Os resultados indicaram que a educação a distância ainda não foi culturalmente assimilada pelos tutores e que superar a distância pode ser ainda mais difícil para profissionais de enfermagem que possuem dupla jornada de trabalho.

PALAVRAS-CHAVE: educação a distância. educação profissionalizante. enfermagem. tutoria.

\footnotetext{
*Trabalho elaborado a partir de dissertação de mestrado (Barbosa, 2004), financiada pelo Programa de Apoio à Pesquisa em Educação à Distância, PAPED-CAPES.

${ }^{1}$ Professora, Universidade Estácio de Sá, Rio de Janeiro. <fatimabarbosa@mls.com.br>

${ }_{2}^{2}$ Professora, Laboratório de Tecnologias Cognitivas, Núcleo de Tecnologia Educacional para a Saúde, Universidade Federal do Rio de Janeiro.<frezende@nutes.ufrj.br>

${ }^{1}$ Av. Presidente Vargas, 642

Centro - Rio de Janeiro, RJ

Brasil - 20.071-001
} 


\section{0 contexto do estudo}

As diretrizes básicas para a política atual de Saúde no Brasil foram elaboradas no âmbito da Constituição de 1988, quando foi implantado o Sistema único de Saúde (SUS), alicerçado no Art. $1^{\circ}$. (da Constituição), que promulga que todos são iguais perante a lei, sem distinção de qualquer natureza, assegurando o acesso universal e igualitário às ações e serviços de saúde para sua promoção, proteção e recuperação, mediante políticas sociais e econômicas (Brasil, 1999).

o sus oferece um novo paradigma no campo da saúde, rompendo de forma decisiva com o modelo médico-assistencial privatista de prestação de serviços $e$ trazendo uma nova concepção de atendimento. Por isso mesmo, a exigência de práticas voltadas para a vigilância à saúde desenvolvidas pelos seus profissionais (Bomfim \& Torrez, 2002). Essas práticas envolvem novos conhecimentos, procedimentos e abordagens sobre: processo saúde-doença, segurança no trabalho, novas maneiras de lidar com o público que procura o Sistema de Saúde, novas funções administrativas e gerenciais, dentre outros. Além disso, os profissionais da área de Enfermagem inseridos nessa prática devem ser capazes de usar conhecimentos científicos e saberes tácitos, razão e emoção, racionalidade e utopia para o exercício do cuidar, verbo "fundante" dos profissionais de Enfermagem, e utilizar as novas práticas profissionais que lhes são exigidas nesse novo cenário (Kuenzer, 2006).

O Ministério da Saúde, considerando as reivindicações da sociedade organizada e a histórica luta da área da saúde, lança, em 1999, o Projeto de Profissionalização dos Trabalhadores da Área de Enfermagem - PROFAE (Brasil, 2002), financiado pelo Banco Internacional para a Reconstrução e o Desenvolvimento (Banco Mundial), Banco Interamericano de Desenvolvimento (BID), Organização das Nações Unidas (ONU), Organização das Nações Unidas para a Educação, a Ciência e a Cultura (UNESCO), Comissão Econômica para a América Latina e o Caribe (CEPAL). Este Projeto está estruturado em dois componentes de atuação: o Componente 1 (Profissionalização e Escolarização), que se ocupa da formação profissional e da complementação do ensino fundamental dos trabalhadores em Enfermagem, e o Componente 2 (Conhecimento e desenvolvimento em Saúde), com o objetivo de "impulsionar as condições que darão sustentabilidade à política de Educação Profissional na área de Saúde" (Torrez, 2001, p.13). Neste componente, é oferecido o Curso de Formação Pedagógica em Educação Profissional na Área de Saúde: Enfermagem (CFPE), em nível de especialização, dirigido aos enfermeiros que exercem a docência nos cursos do Componente 1.

O CFPE é oferecido em todo o Brasil utilizando a modalidade da educação a distância ( $\mathrm{EaD})$, e se apóia em pressupostos teóricos inovadores, materiais educativos impressos, na mediação pedagógica exercida por tutores, e no uso dos recursos tecnológicos da informática. O curso tem como objetivos suprir a necessidade urgente de formar professores especializados no campo da ação educativa na área de saúde (Enfermagem), e oferecer uma alternativa de atualização para os docentes que almejam alcançar melhores níveis de qualificação profissional e autonomia, mediante a utilização dos meios tecnológicos de comunicação e informação.

A modalidade de EaD representa, para os profissionais da saúde, uma alternativa viável para a formação continuada, na medida em que eles não 
precisam se afastar de seu local de trabalho para estudar, fator de grande relevância para essa clientela, com múltiplos vínculos de trabalho (Fiocruz-EaD/ ENSP, 2000).

Tendo em vista o caráter inovador do PROFAE, no que se refere à educação profissional na área de enfermagem, aos princípios pedagógicos adotados no CFPE e à utilização da modalidade de EaD por profissionais que estão desempenhando pela primeira vez o papel de tutores, torna-se importante investigar a prática desses tutores no sentido de realimentar a própria implementação do projeto.

O objetivo geral da pesquisa foi investigar os processos educativos a distância no âmbito do CFPE. O objetivo específico foi caracterizar a prática dos tutores do CFPE em diferentes contextos regionais de atuação, tendo como eixos as seguintes questões norteadoras: Como os tutores se apropriam dos pressupostos pedagógicos e dos materiais educativos do curso?; Como os tutores se apropriam dos meios de comunicação para estabelecer a ação educativa a distância?; e Quais são as principais dificuldades inerentes à prática do tutor do CFPE?

Espera-se contribuir nos aspectos teóricos e práticos para a EaD no contexto da educação profissional em enfermagem, principalmente, no que diz respeito à compreensão do papel dos tutores.

\section{Funções e estratégias do tutor na EaD}

Nas primeiras experiências em EaD, quando os cursos eram oferecidos por correspondência, o ensino se inspirava no modelo fordista de divisão de tarefas, baseadas na transmissão de informação e calcadas no cumprimento de objetivos. O aluno estudava por módulos instrucionais, que tinham a função de ensinar. Nesse modelo, a figura do tutor era praticamente inexistente e sem muito valor, já que ele desempenhava apenas o papel de 'acompanhante' do processo de aprendizagem do aluno. Esse modelo de ensino repercutiu muito negativamente na aceitação da EaD, porque eram identificados, em seus processos, os elementos do modelo fordista da produção industrial (Belloni, 1999).

A partir da década de 1980, acompanhando as mudanças sociais, novas concepções pedagógicas de ensino e aprendizagem passam a influenciar projetos e programas na modalidade a distância (Maggio, 2001). A ênfase que era dada à transmissão de informação e ao cumprimento de objetivos foi substituída pelo apoio à construção do conhecimento $e$ aos processos reflexivos, aparecendo a idéia de tutor como aquele que dá apoio à construção do conhecimento.

Segundo Belloni (1999), a partir de então, passam a coexistir duas orientações teórico-filosóficas no campo da educação e, particularmente, da EaD: o modelo antigo, baseado nos processos "fordistas" de ensino; e o modelo mais moderno, cujos objetivos e estratégias visam a se afastar do behaviorismo de massa em direção a um modelo mais aberto, flexível, humanista e menos tecnocrata (Belloni, 1999). Nesse percurso da EaD, a tutoria passa a ser considerada como um dos fatores fundamentais para o bom desempenho do aluno. Assim, o tutor tem sido objeto de estudo de diversos autores e, de acordo com as concepções pedagógicas do curso no qual ele está envolvido, 
recebe variadas denominações, tais como: orientador, professor, facilitador da aprendizagem, tutor-orientador, tutor-professor, e até mesmo animador de rede. Entretanto, o perfil de tutor ainda não está completamente configurado e, nessa indeterminação de funções, o professor é quem tem ocupado esse lugar. Belloni (1999) lista algumas das funções que o professor está assumindo para desempenhar o papel de tutor na EaD (Quadro 1).

Quadro 1. Funções que o professor assume no papel de tutor.

\begin{tabular}{|c|c|}
\hline Professor no papel de tutor & Função \\
\hline - Professor formador & - Orientar o estudo e a aprendizagem do aluno. \\
\hline $\begin{array}{l}\text { - Conceptor e realizador de } \\
\text { cursos e materiais }\end{array}$ & $\begin{array}{l}\text { - Preparar os planos de estudos, currículos e } \\
\text { programas. }\end{array}$ \\
\hline - Professor pesquisador & - Pesquisar e se atualizar em sua disciplina. \\
\hline - Professor tutor & . Orientar o aluno em seus estudos. \\
\hline - Tecnólogo educacional & $\begin{array}{l}\text { - Organizar pedagogicamente os conteúdos } \\
\text { adequados a cada suporte técnico. }\end{array}$ \\
\hline - Professor "recurso" & - Providenciar respostas às dúvidas do aluno. \\
\hline - Monitor & $\begin{array}{l}\text { - Coordenar grupos de estudo nas ações } \\
\text { presenciais de EaD. }\end{array}$ \\
\hline
\end{tabular}

Garcia Aretio (2001) apresenta três funções para o tutor: a função orientadora, mais centrada na área afetiva, a função acadêmica, mais relacionada ao aspecto cognitivo, e a função institucional, que diz respeito à própria formação acadêmica do tutor, ao relacionamento entre aluno e instituição $e$ ao caráter burocrático desse processo.

A função orientadora se apóia nos processos de integralidade - orientação dirigida a todas as dimensões da pessoa; universalidade - orientação dirigida a todos os orientandos; continuidade - orientação durante todo o processo de ensino-aprendizagem; oportunidade - orientação nos momentos críticos da aprendizagem; e participação - todos os tutores devem participar do processo de aprendizagem do aluno matriculado em mais de uma disciplina na mesma instituição.

$\mathrm{Na} \mathrm{EaD}$, a tutoria pode ser desempenhada de forma presencial, semipresencial ou a distância (Moran, 2005). A modalidade presencial, que se realiza por contatos presenciais com os alunos, individualmente ou em grupos, visa a elucidar questões referentes às dificuldades de conteúdo e dúvidas quanto à metodologia ou aos aspectos estruturais do curso, tais como provas, trabalhos acadêmicos etc. (Belloni, 1999; Landim, 1997; Litwin, 2001; Maggio, 2001). A tutoria semipresencial ainda é o tipo mais utilizado pelos centros que oferecem ensino a distância, por ser considerado o método mais eficaz para a tutoria.

No que diz respeito à tutoria a distância, realizada por meio de correio postal, eletrônico, carta, fax, telefone, Garcia Aretio (2001) alerta que nem sempre o aconselhamento pode ser feito por correio postal ou eletrônico, dado que nem tudo pode ser expresso facilmente por escrito, uma vez que nem todos têm facilidade 
para redigir uma carta ou mensagem eletrônica. O autor aponta o telefone como um meio recomendável para a tutoria a distância, já que permite uma relação imediata $e$ interpessoal com a mesma rapidez com que a relação que poderia acontecer numa sala de aula. Além de poder transmitir informações, resolver problemas pontuais, gerando idéias e reflexões (Garcia Aretio, 2001), a tutoria por telefone, em muitos casos, é um meio de superar a sensação de solidão do aluno nessa modalidade de ensino, além de resolver dúvidas, dar orientação, conectar oralmente tutor e aluno e, em casos específicos, evitar deslocamentos; levando em consideração estas características, a tutoria por telefone tem muitas das funções da tutoria presencial.

\section{O Curso de Formação Pedagógica em Educação Profissional - Enfermagem (CFPE)}

\section{Principais características}

O CFPE é um curso oferecido a distância para graduados, pós-graduados e licenciados em Enfermagem, com carga horária prevista de 660 horas, contando com encontros presenciais entre tutor e aluno e provas presenciais, em sintonia com a lei e decretos que regulamentam a EaD (Brasil, 1998). Nesse curso, o aluno é reconhecido como aluno-enfermeiro-professor e o tutor, em sua maioria mestres e doutores, como tutor-professor. O objetivo das avaliações dos alunos do CFPE privilegia o desenvolvimento de atitudes que, além de contribuírem para uma formação crítico-reflexiva do aluno-enfermeiroprofessor, poderão contribuir também para o desenvolvimento das competências sociopolíticas desse aluno.

Entre os recursos de comunicação utilizados, além dos Correios e Telégrafos, o curso dispõe de uma linha 0800, fax, e tem o apoio complementar de um site na internet, ambiente para veicular informações sobre eventos e seminários, troca de informações entre alunos e tutores, contendo uma biblioteca virtual na qual os alunos têm acesso às notas, aos textos complementares dos módulos impressos e ao "Fale conosco". Esse ambiente é acessado via senhas dos tutores, coordenadores e alunos.

O material didático do CFPE tem como objetivo apoiar as atividades pedagógicas do tutor e do aluno. A elaboração do material didático envolveu uma equipe multidisciplinar de diferentes áreas do conhecimento. Foi desenvolvido pelo Programa de EaD-Fiocruz, especificamente para o curso, por especialistas das áreas de educação e enfermagem privilegiando conteúdos programáticos que garantem estreita $e$ concomitante relação entre teoria $e$ prática. Esse material é composto de 11 módulos impressos, divididos em três núcleos: contextual, estrutural e integrador. Os módulos são organizados de modo a permitirem que o aluno percorra um caminho que parte da educação para a educação profissional e, ao fim, atinja a competência profissional críticoreflexiva. Nos temas dos núcleos contextual e estrutural, os alunos realizam as atividades propostas em cada módulo, enviadas ao tutor para avaliação. Já as atividades propostas nos movimentos do núcleo integrador incluem momentos presenciais, quando o aluno participa de grupos de trabalho nas instituições de educação profissional de nível técnico em saúde. 
Os objetivos do CFPE presumem a aprendizagem orientada para a cidadania, a participação ativa e o desenvolvimento do pensamento crítico. Para isso, o modelo pedagógico do curso utiliza a abordagem problematizadora (Berbel, 1999) como geradora de temas de discussões e debates entre tutor, aluno $e$ grupo, consoantes com a prática cotidiana de um profissional de enfermagem. A prática em enfermagem deve ser orientada pelo comprometimento com o outro, com o social, contemplando um currículo aberto, com possibilidade de trocas entre os atores, e deve orientar seus tutores-professores e alunosprofessores a serem sujeitos de sua práxis pedagógica.

\section{A prática do tutor}

O CFPE pode ser visto como um modelo de EaD que apresenta, em sua estrutura, as características de transição do modelo fordista de ensino para o modelo mais flexível, dinâmico e descentralizado, com uma concepção fundamentada na prática pedagógica crítica e reflexiva, humanista e menos tecnocrata de seus tutores (Freire, 1996, 1994). A proposta pedagógica do curso enfatiza a relação dialógica (Bernstein, 1990; Freire, 1996) que centraliza o processo de ensino-aprendizagem no aluno, no qual o papel do tutor é de parceria, constituindo-se em estímulo para a aprendizagem $e$ incentivo à reflexão.

Neste aspecto, um dos desafios do curso é alavancar essa mudança de papel dos tutores, uma vez que estes vêm de uma "formação de racionalidade técnica de inspiração positivista" (Bomfim \& Torrez, 2002, p.17). Além disso, a relação entre tutores e alunos traz para esses atores algumas dificuldades sobre os limites e ações dessa prática, que esbarram tanto nas questões burocráticas quanto nas questões do discurso pedagógico que se estabelece entre ambos (Bernstein, 1999).

O desenvolvimento do processo pedagógico do curso deve ser apoiado pela tutoria, tanto a distância quanto em momentos presenciais, tendo o aluno como centro do processo educacional e o movimento reflexão na ação como caminho para a construção do conhecimento (Fiocruz-EaD/ENSP, 2000). No entanto, percebe-se que ainda há necessidade de inovações que proporcionem melhor adequação dos processos avaliativos e burocráticos ao modelo pedagógico do curso e à modalidade específica da $\mathrm{EaD}$.

O CFPE prevê que, além da formação acadêmica, com formação a partir da especialização, o tutor tenha um papel diferenciado para atender aos princípios pedagógicos do curso. Para tal, o tutor recebe uma formação inicial, que é oferecida na Oficina de Tutores, visando garantir sua preparação, e um acompanhamento contínuo, propiciado por espaços próprios que visam a incentivar a troca e construção de conhecimentos entre o grupo de tutores.

Coerentemente com os pressupostos pedagógicos do CFPE, o tutor deve orientar o aluno para que esse possa ser gestor de seu próprio conhecimento, assim como dominar um conjunto de técnicas que possibilite a ele planejar seus estudos no que se refere à pesquisa, estruturação de carga horária semanal ou diária de estudo, agendamento dos encontros presenciais etc. Esse planejamento insere-se no âmbito da construção da autonomia do aluno que, ao final do curso, deve estar apto a: atuar como agente multiplicador de concepções de saúde compatíveis com os pressupostos do SUS; e a disseminar 
uma maneira de cuidar que resgate a dignidade do usuário, desperte sua consciência social e respeite sua cidadania.

Em relação à dimensão da comunicação, o CFPE pretende estabelecer entre tutor-professor e aluno-enfermeiro-professor um diálogo criativo, viabilizado pelos meios de comunicação, de modo a tornar a ausência física uma presença quase real. Esse diálogo se alicerça nos pressupostos de Freire (1996), segundo os quais a comunicação dialógica assume as perspectivas filosófica, social, antropológica e histórico-crítica.

O tutor do CFPE tem como tarefa formar professores-profissionais, "que formarão, por sua vez, cuidadores de pessoas". Isto exige dele compromisso ético que, nesse contexto, é a responsabilidade social inerente a quem atua na área de educação, incluindo aí a adoção de relações pautadas no diálogo, respeito, na justiça e solidariedade (Fiocruz-EaD/ENSP, 2000), haja vista que as situações-problema, que surgem como desafios para o profissional de saúde, não podem ser resolvidas apenas com conhecimento técnicocientífico. A prática em saúde requer ações que extrapolam o âmbito puramente científico, no qual a utilização de métodos e técnicas seriam suficientes para dar conta dos resultados a alcançar.

Nesse sentido, o CFPE estabelece que a prática dos tutores deve estar pautada em um conjunto de competências que se baseiam nas competências humanas para a saúde e que estão em sintonia com as funções do tutor, apresentadas no quadro 1.

Dentre suas atividades, o tutor do CFPE deverá propor a discussão de situações-problema do cotidiano profissional do aluno, que é o cerne da metodologia do curso; avaliar os trabalhos elaborados pelos alunos; dar respostas às mensagens eletrônicas dentro da maior brevidade possível; registrar as avaliações do aluno no site do curso; esclarecer dúvidas pessoalmente ou por um dos meios de comunicação; gerir a aprendizagem do aluno, estimulando-o a buscar informações e a formular hipóteses. Essas ações não são predefinidas e pré-modeladas: cada tutor fará seu próprio percurso, carregado de sua experiência como docente, de acordo com a necessidade do aluno e com a situação que ele enfrenta.

Deve-se ressaltar que a prática dos tutores é uma intersecção de diferentes contextos e regida por regulações organizacionais (Nóvoa, 1999), fatos que influenciam na autonomia desses profissionais. Além disso, essa mudança no papel educativo do tutor, requer, tal como para os professores, também uma mudança cultural (Nóvoa, 1999).

\section{Metodologia}

O estudo apresenta uma abordagem quanti-qualitativa tendo um olhar para a compreensão da prática dos tutores do CFPE. Segundo Goldenberg (1999, p.62), "a integração da pesquisa quantitativa e qualitativa permite que o pesquisador faça um cruzamento de suas conclusões de modo a ter mais confiança nos dados". Este tipo de pesquisa permite entrevistar, aplicar questionários, investigar diferentes questões em diferentes ocasiões, utilizar fontes documentais e dados estatísticos (Goldenberg, 1999). Neste estudo foram utilizados o questionário e a entrevista. O questionário foi escolhido como instrumento apropriado para 
colher informações com os tutores em função da localização geográfica variada da população-alvo da pesquisa, levando-se em conta a praticidade para a obtenção de respostas e a facilidade de distribuição do instrumento. Para aprofundar algumas questões, foi escolhida a entrevista, pois esta é, segundo Gil (1994), uma forma de interação social na qual uma das partes está buscando coletar dados e a outra se apresenta como fonte de informação.

O questionário foi elaborado com 55 perguntas fechadas, dez semi-abertas (respostas fechadas e abertas na mesma pergunta) e quatro questões abertas sobre aspectos da prática do tutor e da EaD. Esse questionário foi enviado por correio eletrônico para os coordenadores de Núcleo de Apoio ao Docente-NAD das cinco regiões do Brasil, que deveriam redistribuí-lo para os tutores de seu núcleo. Esse instrumento era acompanhado de uma carta de apresentação na qual se solicitava a participação dos tutores, e mais os termos de consentimento livre e esclarecido para utilização dos dados na pesquisa. Os coordenadores de NAD foram contatados previamente durante uma oficina de capacitação e, nesse encontro, eles se comprometeram a repassar o questionário aos tutores que estavam sob sua coordenação. Do total de 377 tutores trabalhando no projeto na época da pesquisa (2002 a 2004), 67 responderam ao questionário, enviando-o à pesquisadora tanto por correio eletrônico como por correio postal. A amostra do trabalho foi composta por esses 67 tutores que responderam ao questionário.

Foram realizadas entrevistas com uma aluna, uma tutora e com uma coordenadora, gravadas em fita K-7. A transcrição foi literal e todo o conteúdo foi analisado, seguindo as etapas de pré-análise, exploração de material e tratamento dos resultados (Bardin, 1977). A fase de análise e interpretação dos resultados caracterizou-se pelas inferências e interpretações realizadas com base no levantamento dos temas e das categorias da análise de conteúdo. Para isso, foram considerados temas que exprimissem percepções dos tutores sobre a experiência de tutoria.

A soma dos resultados gerados por esses instrumentos compõe um quadro amplo da prática dos tutores do CFPE, que permitiu fazer interpretações $e$ aprofundar questões específicas envolvidas na realidade estudada.

\section{Resultados do estudo}

\section{Caracterização da amostra}

A análise dos dados pessoais da amostra de tutores do CFPE mostrou que a grande maioria dessa população é constituída de mulheres, em média, com 45 anos, brancas, casadas, com filhos e naturais do Estado onde atuam como tutoras.

A faixa salarial dos tutores do CFPE está em torno de dois a quatro mil reais, padrão que pode ser considerado alto para a realidade brasileira em relação ao salário das enfermeiras. O nível salarial dos tutores da região Centro-Oeste se equiparou ao de regiões mais desenvolvidas, como Sul e Sudeste.

A formação dos tutores do CFPE é, majoritariamente, em enfermagem, com mestrado na área de saúde. Parte dos tutores estudados tem doutorado $e$ poucos são especialistas, além de terem cursos de extensão em Informática ou, pelo menos, conhecimentos básicos na área, o que significa que o CFPE possui 
um quadro de tutores com formação adequada para o exercício das funções requeridas.

\section{Apropriação dos pressupostos pedagógicos do CFPE}

Muitos tutores afirmaram que já utilizavam os pressupostos pedagógicos do CFPE no ensino presencial e não apontaram dúvidas quanto ao entendimento desses pressupostos. No entanto, há uma contradição nesse aspecto, na medida em que muitos indicaram o núcleo contextual como o mais difícil, sendo justamente, neste núcleo, discutidos os pressupostos filosóficos e teóricos da educação, os quais fundamentam a formação pedagógica dos alunos. Este resultado pode indicar a dificuldade desses tutores, mestres e doutores em transpor a formação de racionalidade técnica de inspiração positivista para a prática pedagógica crítica e reflexiva, humanista e menos tecnocrata, citada anteriormente.

Para executar um bom trabalho de tutoria, os tutores precisam também do comprometimento dos alunos quanto às atividades que têm de ser desenvolvidas. Entretanto, os tutores responderam que seus alunos não têm apresentado empenho nas leituras complementares, que fazem parte do roteiro de atividades. Isso pode representar mais trabalho para o tutor, que tem de incentivar o aluno a utilizar estratégias para tentar reverter a situação, e também pode repercutir no desempenho do aluno, gerando avaliações negativas.

Os tutores do CFPE dão plantões de quatro horas semanais para os atendimentos presenciais, complementados pela orientação a distância ou presencial de duas a 16 horas semanais. Esse intervalo mostrou que há uma grande diferença quanto ao tempo de dedicação dos professores à tutoria.

Os tutores informaram que dedicam de duas a quatro horas semanais para o estudo do material didático, que, somadas à sobrecarga de atividades cotidianas $e$ profissionais, tornam o trabalho do tutor um exercício oneroso.

Consideraram que a metodologia de EaD é mais difícil de ser assimilada pelo aluno do que por eles. O material didático do curso foi considerado bom pela aluna, pela tutora e pela coordenadora entrevistadas, por oferecer referenciais teóricos que estão modificando a prática educativa tanto do tutor quanto do aluno. Entretanto, apesar de ter sido considerado de boa qualidade pelas entrevistadas, isto não tem garantido que as alunas realizem as leituras complementares sugeridas.

$\mathrm{Na}$ análise da entrevista com a aluna, pôde-se perceber que os aspectos metodológicos do curso e a relação pedagógica entre ela e sua tutora foram os fatores que contribuíram, satisfatoriamente, para a conclusão do curso. A metodologia enfatizada pelos pressupostos teóricos do CFPE foi posta em prática quando a tutora propôs a análise de um problema real, trazido pela aluna, que gerou discussões $e$ atividades posteriores, coerentes com a metodologia da problematização (Berbel, 1998). A atuação da tutora foi considerada, pela aluna, como grande impulsionadora do desempenho no curso, já que criava situações interacionais com o grupo, mobilizando os alunos para a discussão e buscando deles o envolvimento nas tarefas. Para isso, a tutora estimulava o processo comunicacional, estando acessível a qualquer momento. Segundo a aluna, esse diferencial contribuiu para que ela e seus 
pares conseguissem um resultado satisfatório no curso, diferentemente de outros casos de tutores dos quais ela teve notícias por meio de outros alunos.

\section{Apropriação dos meios de comunicação}

Com respeito à utilização dos meios de comunicação, o telefone fixo foi o meio mais utilizado pelos tutores para comunicação com o aluno, seguido do correio eletrônico, celular, fax e correios. Apesar de a infra-estrutura do curso oferecer todos os meios para que a comunicação se efetive, nem sempre os alunos respondem satisfatoriamente à comunicação necessária, demonstrando certa resistência em utilizar os meios disponíveis para a comunicação. Nesse caso, o tutor utilizava o telefone fixo para manter contato, tanto para tirar as dúvidas sobre as atividades do curso, quanto para incentivá-los a permanecer no curso. Muitas vezes, esse incentivo repercutiu numa relação mais imediata e interativa, fato relatado pelos tutores.

A ferramenta "Fale conosco" do site do curso não é utilizada, pois os tutores preferem utilizar seus próprios endereços eletrônicos para comunicação com os coordenadores, alunos e gerência.

\section{Principais dificuldades enfrentadas pelos tutores}

Muitas atividades que o tutor e o aluno desempenham no seu cotidiano são difíceis para ambos, acarretando dificuldades tanto cognitivas (como, por exemplo, não dominar "o processo de internet" ou "entender o processo de EaD"), quanto operacionais (como, por exemplo, "a falta de comunicação com aqueles que não têm email"). Os dados permitem inferir que a modalidade de $\mathrm{EaD}$ ainda não foi culturalmente assimilada pelos tutores do CFPE, já que alguns consideraram que a interação com o aluno é fria $e$ sentem falta do "olho no olho".

Os dados revelaram que o tutor tem dificuldade para dar conta de todas as atividades necessárias à tutoria, e o aluno tem dificuldade para cumprir os prazos estabelecidos pelo curso para entrega de trabalhos, em função da falta de tempo, pois, ambos, tutor e aluno desse curso, têm mais de um emprego (Polak \& Reich, 2002).

Outro problema enfrentado, relatado pelos tutores, diz respeito à comunicação com o aluno, que não é satisfatória, e os motivos que contribuem para isso podem ser não conseguir localizar o aluno ou pela falta de infra-estrutura de telecomunicações de alguns municípios, que impede a comunicação por telefone fixo e correio eletrônico. Mas, mesmo quando os meios estão disponíveis, a comunicação é insuficiente, talvez pela falta da cultura ${ }^{3}$ inerente ao processo educativo a distância.

Os tutores consideram muito trabalhoso desempenhar a tutoria, seja por representar uma sobrecarga de trabalho, seja por ser uma nova experiência para a qual não há modelo predefinido a ser seguido. Para eles, dar conta de todas as exigências que o processo educativo a distância impõe e, ainda, manter a constante interação com o aluno, é um grande desafio.

\author{
${ }^{3}$ Cultura é entendida, \\ aqui, como um \\ conjunto de \\ características humanas \\ que não são inatas, $e$ \\ que se criam ou se \\ preservam ou \\ aprimoram por meio \\ da comunicação e \\ cooperação entre \\ indivíduos em \\ sociedade (Novo \\ Aurélio, século XXI, \\ 1999).
}


A tutora entrevistada revelou que a oficina de tutores não foi vista como uma experiência proveitosa. A tutora apontou alguns pontos negativos da oficina, como o excesso de atividades a executar em um curto espaço de tempo e conversas dispersivas em detrimento da objetividade que seria necessária ao contexto.

A entrevista com a coordenadora revelou suas atribuições relacionadas com a administração educacional do curso e o modo como resolveu questões relacionadas com a preparação dos tutores e com a comunicação entre tutores $e$ alunos, criando pólos estratégicos para oferecer condições de o aluno participar das atividades presenciais, o que pode indicar necessidade de mudança em aspectos da administração do curso.

\section{Conclusões e recomendações}

Os resultados obtidos neste estudo possibilitaram traçar um quadro da prática dos tutores do CFPE e permitiram avançar na compreensão dessa prática. Os resultados indicaram que os tutores do CFPE desempenham a função orientadora (Garcia Aretio, 2001), que visa todas as dimensões da pessoa humana, além da orientação planejada de todo o processo de aprendizagem do aluno. Essa conclusão pode ser um indício de que a prática dos tutores é coerente com a que foi idealizada pela coordenação do curso.

Alguns aspectos da concepção pedagógica adotada pelo curso não foram completamente assimilados no transcorrer das atividades de tutoria. Isto pode ser resultado da dificuldade dos tutores em transpor a proposta pedagógica para a prática. No entanto, há indícios de que os pressupostos teóricos norteadores do construtivismo e da autonomia do aluno (Freire, 1996) foram fatores de impacto na prática dos tutores, sobretudo, se considerada a formação positivista dos profissionais de enfermagem (Torrez, 2001; Carvalho, 2000; Polak \& Reich, 2002).

A modalidade de EaD ainda não foi culturalmente assimilada pelos tutores do CFPE, na medida em que a interação a distância com o aluno é considerada "fria". Essa percepção é aceitável se considerarmos que a cultura brasileira privilegia o contato físico, a comunicação, as relações de vizinhança, diferentemente da cultura européia, na qual se orienta o ensino a distância. Além disso, lidar com a distância pode ser ainda mais difícil para os profissionais de enfermagem, cuja prática se apóia intrinsecamente no contato físico. A questão da dificuldade de tutores e alunos em lidar com a não-presença física precisa ser objeto de estudos futuros sobre EaD. Neste sentido, cabe entender se essa é uma das questões culturais envolvidas no processo educativo a distância e especificamente ligadas ao público-alvo do CFPE, como já citado.

Dada a importância do uso do telefone como meio de comunicação entre tutores e alunos do CFPE, sugere-se o estudo de aspectos metodológicos envolvidos na tutoria utilizando essa mídia, para que se possa, no futuro, obter melhor proveito de sua utilização. O telefone celular também é um meio de comunicação importante no contexto do CFPE, pelo fato de que os alunos do curso se deslocam bastante no seu dia-a-dia em função dos vários empregos. Mas, esse meio pode elevar os custos do curso ou o orçamento do aluno. Essa é uma questão que deve ser levada em consideração no desenvolvimento de 
cursos a distância para atingir profissionais como os do CFPE. Recomenda-se, assim, que seja assegurado o uso do 0800 no curso, e que seja criado um plantão do tutor exclusivamente para atendimento ao telefone, para ajudar tutores e alunos a enfrentarem a barreira da não-presença física e tirarem vantagem desse contato quase presencial.

A questão do uso das tecnologias da informação e comunicação precisa ser discutida no âmbito do CFPE, na medida em que há problemas relativos tanto ao tutor que não usa o "Fale Conosco" do curso, quanto ao aluno que não usa o correio eletrônico satisfatoriamente, mesmo quando dispõem do recurso. Esta questão poderia estar relacionada à falta da cultura de $\mathrm{EaD}$, à falta da apropriação da tecnologia e à ausência das condições ideais, principalmente do tempo livre necessário para o envolvimento no processo educativo a distância, por parte de alunos e tutores.

$\mathrm{Na}$ educação profissional a distância, o fator tempo se revelou de extrema importância, na medida em que tanto tutor quanto aluno têm mais de um emprego, sobrecarga esta que limita o desenvolvimento adequado das atividades. Portanto, recomenda-se que um curso na modalidade de EaD, oferecido para profissionais com perfil como o dos enfermeiros, deve considerar o tempo como uma das maiores dificuldades a serem enfrentadas. Neste sentido, recomenda-se que a estrutura de um curso a distância de formação profissional ofereça flexibilidade nos prazos de envio de tarefas ou de provas, o que poderia diminuir a sobrecarga de trabalho de tutores e alunos.

Outra questão que deve ser levada em consideração é quanto ao consenso sobre o papel que o tutor deve exercer em sua prática junto ao aluno, já que a literatura consultada (Landim, 1997; Maggio, 2001; Litwin, 2001; Garcia Aretio; 2001) aponta uma multiplicidade de papéis para esse profissional. Pelos relatos dos tutores, essa abrangência é um fator que gera insegurança em relação à sua prática, levando-os a necessitar de retorno dos supervisores $e$ dos alunos para balizar sua atuação. Também podem ser objetos de reflexão questões relacionadas à profissionalização do tutor (Nóvoa, 1999) que envolvem a contabilização de aspectos como: tempo real dedicado à tutoria, gastos privados com telefonia e conexão à internet $e$ horas extras de trabalho, o que viria a reduzir a faixa salarial desse profissional. Aponta-se, aqui, a necessidade de uma definição quanto aos papéis, competências $e$ atribuições (Ramos, 2001) desse profissional.

Visando criar uma memória da prática pedagógica dos tutores do CFPE, recomenda-se o registro, pela coordenação do curso, das experiências desses tutores, de modo a gerar um banco de dados a ser disponibilizado tanto em material impresso quanto no site do curso. Na comunidade de tutores do CFPE, essas informações poderiam ser discutidas, o que possivelmente levaria ao enriquecimento de sua prática (Perrenoud et al., 2001). A divulgação mais ampla desse banco de experiências poderia servir, ainda, de base para a prática de tutores de outros cursos a distância que tenham como contexto a educação profissional. 


\section{Referências}

BARBOSA, M. F. S. O. A prática dos tutores do Curso de Formação Pedagógica em Educação Profissional - Enfermagem do PROFAE. 2004. Dissertação (Mestrado) - Programa de Pós-

graduação em Tecnologia Educacional nas Ciências da Saúde, Universidade Federal do Rio de Janeiro, Rio de Janeiro.

BARDIN, L. Análise de conteúdo. Lisboa: Edições 70, 1977.

BELLONI, M. L. Educação a distância. Campinas: Autores Associados, 1999.

BERBEL, N. A. N. Conversando sobre duas propostas metodológicas inovadoras: a aprendizagem baseada em problemas e a metodologia da problematização. In: Questões de ensino na Universidade: conversas com quem gosta de aprender para ensinar. Londrina-PR: Ed. UEL, 1998. p.131-8.

BERNSTEIN, B. A estruturação do discurso pedagógico: classe, código e controle. Petrópolis: Vozes, 1990.

BOMFIM, M. I. R. M.; TORREZ, M. B. A formação do formador no PROFAE: refletindo sobre uma proposta na área de enfermagem. Rev. Formação, v.2, n.4, p.15-34, 2002.

BRASIL. Ministério da Educação e Cultura. Decreto n. ${ }^{\circ}$ 2.494, de 10 de fevereiro de 1998. Disponível em: <http://www.mec.gov.br/Sesu/ftp/dec_2494.doc>. Acesso em: 10 jan., 2006.

BRASIL. Ministério da Saúde. PROFAE - Projeto de Profissionalização dos Trabalhadores da Área de Enfermagem, 1999. Disponível em: <http://www.profae.gov.br/pagina_qualifica.htm>. Acesso em: 23 jun. 2002.

CARVALHO, A. I. A educação a distância e a nova saúde pública. Rio de Janeiro: Fiocruz, 2000.

FREIRE, P. Pedagogia da autonomia: saberes necessários à prática educativa. São Paulo: Paz e Terra, 1996. (Coleção Leitura).

FREIRE, P. A educação como prática da liberdade. Rio de Janeiro: Paz e Terra, 1994.

FIOCRUZ-EaD/ENSP. Formação de tutores para o Curso de Formação Pedagógica em Educação Profissional na Área de Saúde: Enfermagem. Rio de Janeiro, 2000.

GARCIAARETIO, L. La educación a distancia: de la teoría a la práctica. Barcelona: Ariel Educación, 2001.

GIL, A. C. Métodos e técnicas de pesquisa social. 4.ed. São Paulo: Atlas, 1994.

GOLDENBERG, M. A arte de pesquisar: como fazer pesquisa qualitativa em Ciências Sociais. Rio de Janeiro: Record, 1999.

KUENZER, A. Z. Educação profissional: categorias para uma nova pedagogia do trabalho. Bol. Téc. SENAC, v.25, n.2, 1999. Disponível em: <http://www.senac.br/informativo/BTS/252/boltec252b.htm>. Acesso em: 10 jan. 2006.

LANDIM, C. M. M. P. F. Educação a distância: algumas considerações. Rio de Janeiro: Edição da autora, 1997.

LITWIN, E. (Org.). Educação a distância: temas para o debate de uma nova agenda educativa. Porto Alegre: Artmed, 2001.

MAGGIO, M. O tutor na educação a distância. In: LITWIN, E. (Org.). Educação a distância: temas para um debate de uma nova agenda educativa. Porto Alegre: Artmed, 2001. p.93-110.

MORAN, J. M. O que é educação a distância. Disponível em: <http://www.eca.usp.br/prof/moran/ dist.htm>. Acesso em: 20 dez. 2005.

NÓVOA, A. (Org.). O passado e o presente dos professores. In: Profissão

professor. Porto: Porto, 1999. p.7-34. 
BARBOSA, M. F. S. O.; REZENDE, F.

PERRENOUD, P.; PAQUAY, L.; ALTET, M.; CHARLIER, E. Formando professores profissionais: três conjuntos de questões. In: LÉOPOLD, P.; PERRENOUD, P.; ALTET, M.; CHARLIER, É. (Orgs.). Formando professores profissionais: quais estratégias? Quais competências? Porto Alegre: Artmed, 2001. p.12-22.

POLAK, Y. N. S.; REICH, S. T. S. Abrindo trilhas, descortinando novos horizontes na educação a distância. Formação (Brasília), v.2, n.4, p.59-72, 2002.

RAMOS, M. N. A pedagogia das competências e a psicologização das questões sociais. Bol. Téc.

Senac, v.27, n.3, p.27-35, 2001.

SCHÖN, D. A. Educando o profissional reflexivo: um novo design para o ensino e a aprendizagem. Porto Alegre: Artes Médicas, 2000.

TORREZ, M. N. F. B. Formação pedagógica em educação profissional a distância: profissionalizando o docente em saúde. Olho Mágico, v.8, n.3 p.11-3, 2001.

BARBOSA, M. F. S. O.; REZENDE, F. La práctica de tutores en un programa de formación pedagógica a distancia: progresos y desafíos. Interface - Comunic., Saúde, Educ., v.10, n.20, p.473-86, jul/dez 2006.

Este trabajo fue realizado en el ámbito del programa de formación pedagógica profesional a distancia para trabajadores del área de enfermería, buscando entender la práctica, los obstáculos y los desafíos de los tutores en la acción educativa a distancia. Los obstáculos principales relatados por los tutores fueron: dificultad en asimilar el modelo pedagógico constructivista en sus actividades pasar de la propuesta pedagógica a la práctica); dificultad en la asimilación de nuevas tecnologías; falta de infraestructura de telecomunicaciones de algunas ciudades; dificultad en realizar las actividades necesarias para el desarrollo del curso, por falta de tiempo. Los tutores consideraron un desafío desempeñar la tutoría ya que representa una nueva experiencia para la cual no hay modelo predefinido a ser seguido. Los resultados sugieren que la modalidad de la Educación a Distancia no fue aún culturalmente asimilada por los tutores y que superar la distancia puede ser todavía más difícil para los profesionales de Enfermería, debido a que tienen doble jornada de trabajo

PALABRAS CLAVE: educación a distancia. educación profesional. enfermería. tutoria. 